\title{
Kemik İliği Biyopsisi ile Tanı Alan Karsinom Metastazlı Hastalarımız
}

\author{
Patients with Carcinoma Metastasis Diagnosed By Bone Marrow Biopsy
}

${ }^{1}$ Filiz Yavaşoğlu, ${ }^{2}$ Çiğdem Özdemir

${ }^{1}$ Afyonkarahisar Sağlık Bilimleri Üniversitesi Tip Fakültesi Hematoloji Bilim Dall,

Afyonkarahisar, Türkiye

${ }^{2}$ Afyonkarahisar Sağlık Bilimleri Üniversitesi Tip Fakültesi Tibbi Patoloji Anabilim Dall,Afyonkarahisar, Türkiye

Correspondence:

Filiz YAVAŞOĞLU

Afyonkarahisar Sağlık Bilimleri

Üniversitesi Tip Fakültesi Hematoloji

Bilim Dalı,Afyonkarahisar, Türkiye

e-mail:drfilizyavasoglu@gmail.com

\section{Özet}

Solid tümörlerin kemik iliğinde tutulum yaptığı bilinmektedir. Ancak kemik iliği tutulumu ile tanı alması nadirdir. Klinik ve laboratuvar bulguları karakteristik değildir ve farklı ön tanıların düşünülmesine yol açabilmektedir. Kemik iliğinde tutulum saptandığı zaman tedavi yaklaşımını da etkilemekte ve kötü prognozla ilişkilidir. AMAÇ: Kemik iliği tutulumu ile tanı alan solid tümörlü hastalarımızın klinik ve laboratuvar özelliklerini anlatmayı amaçladık. MATERYAL- METOD: Hematolojik malignite ön tanısı ile kemik iliği biyopsisi yapılan ve karsinom metastazı tanısı alan 7 hasta retrospektif olarak değerlendirildi. 3 'ü erkek, 4'ü kadın has-

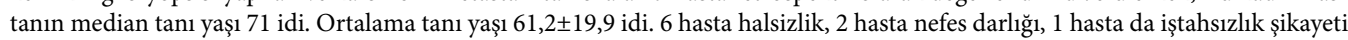
ile başvurmustu. Hastaların hepsinde anemi, 6 hastada trombositopeni, 6 hastada eritrosit sedimentasyon hızı (ESH) yüksekliği, 3 hastada lökositoz mevcut idi. 4 hastada meme kanseri, 2 hastada mide, 1 hastada prostat karsinom tutulumu saptandı. Tanı konan hastaların median sağ kalım süreleri 20 ay (2-33 ay) olarak saptanmıştır. 2 meme kanseri ve 1 prostat kanserli hasta hormonoterapi ile yaşamlarını sürdürmektedirler. SONUÇ: Kemik iliği biyopsisi; kemik iliğinde tutulum yapan hastalıkları saptamada ucuz, kolay uygulanabilen ve etkin bir yöntemdir.

Anahtar Kelimeler: Kemik İliği Metastazı, Solid Tümör, Anemi, Trombositopeni

\section{Abstract}

It is known that solid tumors are involved in the bone marrow. However, it is rare to be diagnosed with bone marrow involvement. Clinical and laboratory findings are not characteristic and may lead to the consideration of different prediagnoses. When bone marrow involvement is detected, it also affects the treatment approach and is associated with a poor prognosis. We aimed to describe the clinical and laboratory characteristics of our patients with solid tumors diagnosed with bone marrow involvement. Seven patients who underwent bone marrow biopsy with the pre-diagnosis of hematological malignancy and were diagnosed with carcinoma metastasis were evaluated retrospectively. The median age at diagnosis of 3 male and 4 female patients was 71 . The mean age at diagnosis was $61,2 \pm 19,9.6$ patients presented with fatigue, 2 patients with shortness of breath, and 1 patient with anorexia. All patients had anemia, 6 patients had thrombocytopenia, 6 patients had increased sedimentation, and 3 patients had leukocytosis. Breast cancer in 4 patients, gastric carcinoma in 2 patients, and prostate carcinoma in 1 patient were detected. The median survival time of the diagnosed patients was 20 months (2-33 months). 2 breast cancer and 1 prostate cancer patients continue their lives with hormone therapy. Bone marrow biopsy; is a cheap, easily applicable and effective method for detecting diseases involving the bone marrow.

Keywords: Bone Marrow Metastasis, Solid Malignancy, Anemia, Thrombocytopenia 


\section{Giriş}

Kemik iliği, myeloid ve lenfoid hematolojik malignitelerde s1klikla tutulum yerlerindendir. Kan hücrelerinin üretim yeri olması nedeniyle kemik iliğinde tutulum olan hastalar anemi semptomları, nötropeniye bağlı enfeksiyonlar, trombositopeniye bağlı kanama bulguları ile karşımıza gelebilmektedir. Solid tümörler de kemik iliğinde tutulum yapabilmektedir. Kemik iliğine en sik metastaz yapan tümörler akciğer, meme, mide ve prostattır (1-2). Ancak malignite tanisı olmayan vakalarda kemik iliği metastazı ile malignite tanısı almaları nadir rastlanan durumlar arasında yer almaktadır. Kemik iliğinde metastaz saptandığı zaman, primer malignitenin orjini hakkında fikir verebilmektedir ve primer malignite, prognozu belirleyen ana etmenlerden biridir.

Kemik iliği tutulumu olsa bile bazen laboratuvar testleri ve görüntüleme yöntemleri ile primer tümörün yeri bulunamayabilmektedir. İmmünhistokimyasal incelemeler bize tümör orjini konusunda yol göstermektedir. Sitokeratin pozitifliği epitelyal bir tümörü düşündürürken, TTF-1; primer veya sekonder akciğer kanserini, PSA; prostattan köken aldığını düşündürmektedir (3-6) (Resim 1,2).

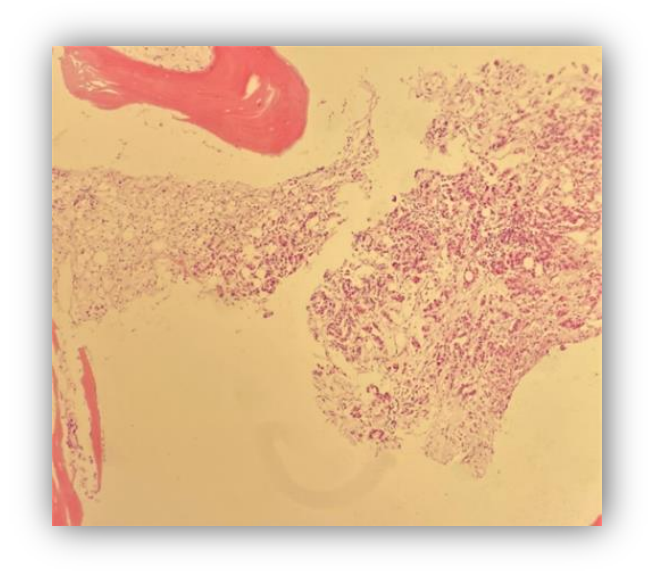

Resim 1. Kemik iliğine ait hücresel elemanların neredeyse tamamının yerini alan, bă̆ dokudan zengin stroma oluşturan, adenoid yapılardan oluşan infiltratif karsinom (HEX100).

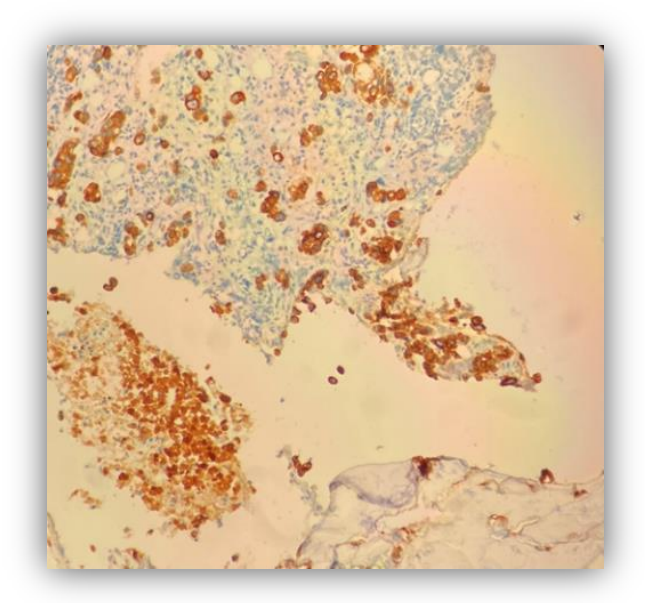

Resim 2. Kemik iliği infiltrasyonu yapan karsinomda immünhistokimyasal çalışmada diffüz kuvvetli keratin ekspresyonu (X100) 


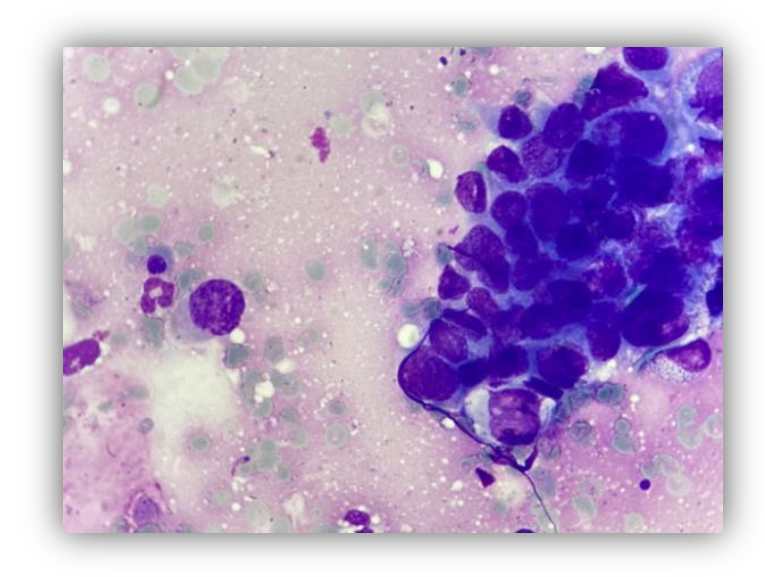

Resim 3. Kemik iliği imprintinde bazen tek tek duran genellikle üç boyutlu büyük gruplar yapan, kemik iliği hücrelerine göre oldukça büyük boyutta, nükleolu belirgin pleomorfik nükleuslu, geniş sitoplazmalı malign hücre gruplarl (X1000, immersiyon yağl).

Biz de kliniğimizde hematolojik malignite ön tanısı ile kemik iliği biyopsisi yapılmış ve karsinom tanısı almış vakalarımızın klinikopatolojik bulgularını anlatmayı amaçladık.

\section{Gereç ve Yöntemler}

$\mathrm{Bu}$ çalışmamızda Afyonkarahisar Sağlık Bilimleri Üniversitesi Hastanesi Hematoloji Kliniğinde hematolojik malignite şüphesi ile kemik iliği biyopsisi yapılmış ve adenokarsinom tanısı almış hastaların klinikopatolojik bulguları, yaşam süreleri, kemik iliği fibrozis bulguları belirlenmesi amaçlanmıştır.

Hastalara crista ilica posterior superiordan 10 cc lidokain ile lokal anestezi uygulandiktan sonra $11 \mathrm{G}$ uzunluğundaki kemik iliği biyopsi seti ile kemik iliği biyopsisi işlemi yapılmıştır. İşlem sonrası komplikasyon gelişmeyen hastaların dosya verileri retrospektif olarak incelendi.

Erkeklerde $\mathrm{Hb}<13 \mathrm{~g} / \mathrm{dL}$, kadınlarda $\mathrm{Hb}<12$ $\mathrm{g} / \mathrm{dL}$ anemi olarak değerlendirildi. Lökosit say1s1 $<4000 / \mathrm{mm} 3$ lökopeni; nötrofil sayıs1 $<1500 / \mathrm{mm} 3$ nötropeni ve trombosit sayıs1 $<100,000 / \mathrm{mm} 3$ trombositopeni olarak değerlendirildi.
İstatistiksel analiz çalışmada elde edilen bulguların istatistiksel değerlendirmesi için SPSS for Windows sürüm 21,0 kullanıldı. Ölçümsel değişkenler ortalama \pm standart sapma (SD) olarak, kategorik veriler ise say1 ve $\%$ olarak ifade edildi. Hastaların ortalama yaşam sürelerinin belirlenmesinde Kaplan Meier analizi kullanıldı. $\mathrm{P}<0,05$ anlamlı kabul edildi.

Etik kurul onayı: Afyonkarahisar Sağlık Bilimleri Üniversitesi Klinik Araştırmalar Etik kurulu 05.05.2020 tarih ve 2020/172 sayılı kararı ile etik kurul onayı alınmıştır.

\section{Sonuçlar}

1 Ocak 2017- 1 Ocak 2020 tarihleri arasında kemik iliği biyopsisi yapılmış 433 hastadan 7 tanesine kemik iliği biyopsisi ile karsinom tanısı konmuştur. Median yaş: 71 (28-80) , ortalama tanı yaşı $61,2 \pm 19,9$ olan 7 hastanın 4 'ü kadın 3'ü erkektir. 1 hastaya multipl myelom, 3 hastaya akut lösemi, 3 hastaya da Myelodisplastik sendrom ön tanısı ile kemik iliği biyopsisi yapılmıştı. Hastaların başvuru semptomları, laboratuvar bulguları ve tanıları tablo 1'de özetlenmiştir. 
Tablo 1. Hastaların klinik ve laboratuvar özellikleri

\begin{tabular}{|c|c|c|c|c|c|c|c|c|c|c|c|c|c|c|}
\hline $\begin{array}{l}\text { Hasta } \\
\text { no }\end{array}$ & Şikayet & $\begin{array}{l}\text { Cinsiy } \\
\text { et }\end{array}$ & $\begin{array}{l}\text { ES } \\
\mathbf{H}\end{array}$ & $\begin{array}{l}\text { Ya } \\
\text { ș }\end{array}$ & Wbc & $\mathbf{H b}$ & Mev & Neu & PIt & LDH & Periferik yayma bulguları & $\begin{array}{l}\text { Primer } \\
\text { malignit } \\
\text { e }\end{array}$ & Ön tanı & OS \\
\hline 1 & $\begin{array}{l}\text { iştahsızlı } \\
\mathrm{k}, \\
\text { halsizlik }\end{array}$ & kadın & 76 & 38 & 8790 & 10,5 & 94 & $\begin{array}{l}247 \\
0\end{array}$ & $\begin{array}{l}102 * 10^{\wedge} \\
3\end{array}$ & 765 & $\begin{array}{lr}\text { Eritrositler } & \text { normokrom } \\
\text { normositer, } & \text { Trombositopeni }\end{array}$ & meme & MDS & 33 ay \\
\hline 2 & halsizlik & kadın & 111 & 74 & 6700 & 7,6 & 97 & $\begin{array}{l}367 \\
0\end{array}$ & $70 * 10^{\wedge} 3$ & 224 & $\begin{array}{l}\text { Eritrositlerde rulo formasyonu, } \\
\text { Trombositopeni }\end{array}$ & meme & MDS & 31 ay \\
\hline 3 & halsizlik & kadın & 94 & 41 & 6990 & 9,7 & 93 & $\begin{array}{l}304 \\
0\end{array}$ & $\begin{array}{l}216^{*} 10^{\wedge} \\
3\end{array}$ & 278 & Eritrositlerde rulo formasyonu & meme & $\begin{array}{l}\text { Multipl } \\
\text { myelom }\end{array}$ & 31 ay \\
\hline 4 & $\begin{array}{l}\text { nefes } \\
\text { darlığ1 }\end{array}$ & erkek & 110 & 71 & 5000 & 6 & 99 & $\begin{array}{l}309 \\
0\end{array}$ & $19 * 10^{\wedge} 3$ & 2012 & $\begin{array}{l}\text { Eritrositlerde rulo formasyonu, } \\
\text { Trombositopeni, atipik lenfosit }\end{array}$ & mide & $\begin{array}{l}\text { Akut } \\
\text { lösemi }\end{array}$ & 3 ay \\
\hline 5 & halsizlik & kadın & 137 & 77 & 17890 & 9,1 & 94 & $\begin{array}{l}876 \\
0\end{array}$ & $73 * 10^{\wedge} 3$ & 528 & $\begin{array}{l}\text { Eritrositlerde rulo formasyonu, } \\
\text { Trombositopeni, atipik lenfosit }\end{array}$ & meme & $\begin{array}{l}\text { Akut } \\
\text { lösemi }\end{array}$ & 5 ay \\
\hline 6 & $\begin{array}{l}\text { halsizlik, } \\
\text { nefes } \\
\text { darılığ }\end{array}$ & erkek & 19 & 80 & 4840 & 12,5 & 90 & $\begin{array}{l}334 \\
0\end{array}$ & $78 * 10^{\wedge} 3$ & 491 & Trombositopeni & prostat & MDS & 20 ay \\
\hline 7 & halsizlik & erkek & 41 & 58 & 12090 & 5,2 & 95 & $\begin{array}{l}334 \\
0\end{array}$ & $9^{*} 10^{\wedge} 3$ & 2150 & $\begin{array}{lr}\text { Eritrositler } & \text { normokrom } \\
\text { normositer, } & \text { poikiloanizositoz, } \\
\text { nötrofillerde } & \text { displastik } \\
\text { değişiklikler, trombositopeni }\end{array}$ & mide & $\begin{array}{l}\text { Akut } \\
\text { lösemi }\end{array}$ & 5 ay \\
\hline
\end{tabular}

(ESH: Eritrosit sedimentasyon hizl, WBC: lökosit sayısl, Hb: hemoglobin, MCV: ortalama eritrosit hacmi, Neu: absolü nötrofil saylsl, PLT: trombosit saylsl, LDH: Laktat dehidrogenaz)

3 hasta tanı konulduktan ortalama 5 ay sonra ex olmuştur. Ex olan hastaların primer tanılarına bakıldığında mide ca tanısı alan 2 hasta ve meme ca tanısı alan bir hasta hayatını kaybetmiştir. Tanı konan hastaların sağ kalım süreleri median 20 ay (2-33 ay) olarak saptanmıştır. Yapılan kemik iliği incelemelerinde fibrozis saptanmamıştır.

\section{Tartış̧ma}

Kemik iliği biyopsisi sitopeniler, açıklanamayan anemiler, periferik yaymada kemik iliği tutulumunu düşündüren bulgular olduğunda, malign hematolojik hastalıkların tanisinda, evrelemesinde ve takibinde kullanılan yöntemdir. Solid tümörlerin de kemik iliğinde tutulum yaptığı bilinmektedir. Dolaşımdaki tümör hücreleri kanlanması iyi olan kemik iliğine hematojen yayılım gösterebilmektedirler. Kemik iliğini infiltre eden tümör hücreleri ve salgilanan sitokinler nedeniyle; kemik iliği hücre yapısı ve mikroçevresi etkilenmekte, buna bağlı olarak da hematopoez inhibe olmaktadır (7). Anemi, trombositopeni, lökopeni ortaya çıkabilmektedir. Bazen de kemik iliğinde tutulum olsa bile, hemograma yansımayabilmektedir. Kemik iliği tutulumu solid tümörlerin sık tutulum yaptığı yerlerden biri değildir, ancak survey ve tedaviyi etkileyen tutulum yerlerinden biridir (8). Kemik iliğine en s1k metastaz yapan tümörler meme ve prostat kanseridir. \%70-80 kemik iliği tutulumu yapabilmektedir (9-10). Ancak kemik iliği tutulumu ile hastaların tanı alması nadirdir.

Kemik iliği tutulumu olan solid tümörlü 73 hastanın değerlendirildiği bir çalışmada trombositopenisi olan hastalarda median yaşam süresi olmayanlara göre daha k1sa bulunmuştur (11). 25 hastanın değerlendirildiği başka bir çalışmada da trombositopenisi olan hastalarda yaşam süresi daha kısa olarak saptanmıştır (12).

10112 kemik iliği örneğinin değerlendirildiğ bir çalışmada 101 hastada kemik iliği metastazı saptanmış (\%1), en sık metastaz yapan tümörler akciğer kanseri, mide kanseri, meme ve prostat kanseri olarak saptanmıştır (13). Fei ve arkadaşlarının 7006 tane kemik iliği incelemesinde nonhematolojik tümör 
metastazı saptama oran1 $\% 0,3$ olarak saptamışlardır (14).

3345 kemik iliği biyopsisinin değerlendirildiği Türkiye'de yapılmış bir çalışmada 58 hastada kemik iliği metastazı saptanmış. En sık saptanan tümörler meme kanseri, primeri bilinmeyen, prostat ve akciğer kanseri imiş. 58 hastanın 39 tanesinin önceden kanser tanıs1 bilinmekte imiş. 19 hastaya kemik iliği biyopsisi ile solid tümör tanısı konulmuştur. Kemik iliği biyopsisi ile solid tümör tanıs1 konma oranı $\% 0,5$ olarak saptanmıştır (15). Bizim çalışmamızda da kemik iliği biyopsisi ile solid tümör tanısı konma oran1 \%1 olarak saptanmıştır. Bizim çalışmamızda da en sık tutulum yapan malignite meme kanseridir. Çalışmamızda insidansın diğer çalışmalara göre yüksek çıkmasının nedeni yaşlanma ile birlikte kanser insidansının artmasıdır ki, bizim 4 hastamızın tanı yaşı $>70$ idi.

Pek çok laboratuvar ve klinik bulgu kemik iliği tutulumu olduğunu düşündürebilmektedir; mikroanjiopatik hemolitik anemi, artmış eritrosit dağılım genişliği (RDW), artmış laktat dehidrogenaz (LDH), alkalen fosfataz (ALP), ürik asit, lökoeritroblastik değişiklikler kemik iliği tutulumunu düşündüren bulgulardır ancak tanısal önemleri net değildir (16). Chauhan ve ark. yaptı̆̆ 1 çalışmada en sik saptanan biyokimyasal değişiklik LDH yüksekliğidir (17).

Özkalemkaş ve ark. yaptığı çalışmada en sık saptanan biyokimyasal değişiklik hiperkalsemi imiş (18). Bizim çalışmamızda da en sık saptanan biyokimyasal değişiklik LDH yüksekliği idi. 7 hastanın 6'sında LDH yüksekliği mevcut idi.

Solid tümör kemik iliği tutulumu olan hastalarda klinik ve laboratuvar bulguları karakteristik değildir. Mevcut bulgular ile hematolojik maligniteleri taklit edebilmektedir. Kemik iliğinde tutulum saptandığı zaman; tedavi kararı için önemli etkilere sahiptir ve kötü prognozla ilişkilidir (18-20).

Meme kanseri kemik iliğine en sık metastaz yapan tümörlerden biridir. Ancak kemik iliğinden meme kanseri tanısı konması çok nadirdir. Sadece \%0.17 saptanabilen bir durumdur (21). Kemik iliği tutulumu olan meme kanserli 22 hastanın değerlendirildiği bir çalışmada; hastaların en sık bulgusu anemi idi ve 23-46 ayda tanı alabilmişler (22). Bizim çalışmamızda da 4 hastaya kemik iliği biyopsisi ile meme kanseri tanısı koyduk. Ve bu dört hastanın bir tanesinde memelerde kitlesel oluşum, meme kanseri bulgusu olmamasına rağmen kemik iliği biyopsisi ile meme kanseri tanısı almıştır (Resim 3). Memede kitlesel oluşum olmasa bile kemik iliğindeki hormonal duruma göre hastalar hormonoterapiden faydalanabilmektedir. Bizim hastamız hormoterapi ile de 33 ay yaşam sürebilmiştir.

Prostat karsinomlu olgularda kemiklerde tutulum olmadan da kemik iliğinde tutulum saptanabilmektedir (23). Prostat spesifik antijen genellikle pozitiftir (24) . Bizim prostat ca tanıs koyduğumuz hastamızda tanı anında iskelet sisteminde de yaygin tutulum mevcuttu ve total prostat spesifik antijen düzeyi: $673 \mathrm{ng} / \mathrm{mL}(0-4)$ olarak saptanmıştı.

Meme kanseri tanısı alan 4 hastamızın östrojen ve progesteron reseptörleri pozitif olarak saptanmıştır. Ve kemiklerde yaygın litik lezyonları mevcuttur. Kamby ve ark. yaptığı çalışmada meme kanseri kemik iliği tutulumu sonucunda; kemiklerde tutulum olabileceğini belirtmişlerdir (25).

Kopp ve ark. yaptığı kemik iliği tutulumu olan 22 meme kanserli hastaların değerlendirildiği bir çalışmada kemik iliği tutulumu olan hastaların hepsinde kemik tutulumunun da olduğunu belirtmişlerdir (26).

\section{Sonuç}

Kanser hastalarında kemik iliği tutulumu gösteren direkt bir bulgu bulunmamaktadır. Solid tümörlerde kemik iliği tutulumu sık rastlanmasına rağmen, kemik iliğinden solid tümör tanıs1 konmas1 nadir bir durumdur. Kemik iliği biyopsisi; solid malignite evrelemesinde rutin kullanılan bir tanısal yöntem değildir. Açıklanamayan hematolojik bulgular, trombositopeni, klinisyeni uyarıc1 bulgular olabilmektedir. Kemik iliğinden tanı aldıklarında hastalar açısından survey kısa, etkili kemoterapi alma şansı azalmaktadır. 
Kemik iliği biyopsi hematolojik malignite tanısında etkili bir yöntem olduğu kadar solid tümör kemik iliği tutulumunu saptamada da etkin, ucuz ve uygulanabilir bir yöntemdir.

\section{KAYNAKLAR}

1. Krishnan C, George TI, Arber DA. Bone marrow metastases: a survey of nonhematologic metastases with immunohistochemical study of metastatic carcinomas. Appl Immunohistochem Mol Morphol 2007; 15: 1-7.

2. Sharma S, Murari M. Bone marrow involvement by metastatic solid tumors. Indian $J$ Pathol Microbiol 2003; 46: 382-384

3. Chu P, Wu E, Weiss LM. Cytokeratin 7 and cytokeratin 20 expression in epithelial neoplasms: a survey of 435 cases. Mod Pathol. $2000 ; 13: 962$ 72.

4. Kitamura H, Yazawa T, Sato H, Okudela K, Shimoyamada H. Small cell lung cancer: significance of RB alterations and TTF-1 expression in its carcinogenesis, phenotype, and biology. Endocr Pathol. 2009 ;20:101-7.

5. Cuzick J, Thorat MA, Andriole G, Brawley OW, Brown PH, Culig Z, Eeles RA, Ford LG, Hamdy FC, Holmberg L, Ilic D, Key TJ, La Vecchia C, Lilja H, Marberger M, Meyskens FL, Minasian LM, Parker C, Parnes HL, Perner S, Rittenhouse H, Schalken J, Schmid HP, Schmitz-Dräger BJ, Schröder FH, Stenzl A, Tombal B, Wilt TJ, Wolk A. Prevention and early detection of prostate cancer. Lancet Oncol. 2014;15:484-92.

6. Mostofi FK, Davis CJ Jr, Sesterhenn IA Pathology of carcinoma of the prostate. Cancer. 1992;70:235-53

7. Sterling JA, Edwards JR, Martin TJ, Mundy GR Advances in the biology of bone metastasis: how the skeleton affects tumor behavior. Bone. 2011 ;48:6-15.

8. Banys M, Solomayer EF, Becker S, Krawczyk N, Gardanis K, Staebler A, Neubauer H, Wallwiener D, Fehm T. Disseminated tumor cells in bone marrow may affect prognosis of patients with gynecologic malignancies. Int $J$ Gynecol Cancer 2009;19:948-52.

9. Kuchuk I, Hutton B, Moretto P, Ng T, Addison $\mathrm{CL}$, Clemons $\mathrm{M}$. Incidence, consequences and treatment of bone metastases in breast cancer patients-experience from a single cancer centre. $J$ Bone Oncol 2013;2:137-44.

10. Coleman RE. Metastatic bone disease: clinical features, pathophysiology and treatment strategies. Cancer Treat Rev 2001; 27:165-76.

11. Kiliçkap, S., Erman, M., Dınçer, M., Aksoy, S., Harputluoğlu, H., \& Yalçin, S. Bone marrow metastasis of solid tumors: Clinicopathological evaluation of 73 cases. Turkish Journal of Cancer, 2007;37:85-88.

12. Wong KF, Chan JK, Ma SK: Solid tumour with initial presentation in the bone marrow-a clinicopathologic study of 25 adult cases. Hematol Oncol. 1993, 11:35-42. 